\title{
Multistage Investment Actions with the Emission Cap
}

\author{
Mingrong Wang, ${ }^{1}$ Mingxi Wang, ${ }^{2}$ Yi Hu, ${ }^{3}$ and Haibin $\mathrm{Xie}^{4}$ \\ ${ }^{1}$ School of Economics, Capital University of Economics and Business, Beijing 100070, China \\ ${ }^{2}$ School of International Trade and Economics, University of International Business and Economics, Beijing 100029, China \\ ${ }^{3}$ School of Economics and Management, University of Chinese Academy of Sciences, Beijing 100190, China \\ ${ }^{4}$ School of Banking and Finance, University of International Business and Economics, Beijing 100029, China
}

Correspondence should be addressed to Yi Hu; huyi@ucas.ac.cn

Received 15 December 2015; Accepted 1 February 2016

Academic Editor: Francesco Pesavento

Copyright (C) 2016 Mingrong Wang et al. This is an open access article distributed under the Creative Commons Attribution License, which permits unrestricted use, distribution, and reproduction in any medium, provided the original work is properly cited.

To achieve the emission reduction target in 2020, China plans to establish a nationwide carbon trading market during 2016-2019. It is therefore an important but difficult task for policymakers to set emission allowances and allocate them among entities. There are three alternative allocation rules, which vary from free of charge to full auctioning. For business managers, the question is whether one of these rules meets the emission cap at the minimum cost. Based on China's emission-abatement target, this paper examines the optimal investment and analyzes its implementation in different allocation rules. A new model is developed to formulate enterprises' emission reduction pathways and the cost-minimization problem with the emission cap. The results show that the magnitude of enterprises' emission reduction is positively related to their innovation potential; neither auctioning nor being free of charge can make enterprise's individual emission-abatement investment in accordance with the optimal level; enterprise's individual emissionabatement investment is sensitive to efficiency, budget cap, and environmental benefit. This paper discusses simultaneously their policy implications for China.

\section{Introduction}

To meet the target of reducing carbon emissions per unit of GDP by 40 to 45 per cent by 2020 relative to 2005 levels, China today is looking for market-based instruments such as carbon tax and emission trading as potential tools to reduce the carbon intensity of its economy. The basic principle of carbon tax is to internalize externalities associated with carbon emissions, while the main objective of carbon emission trading enforces plants and factories to meet the emission cap by fiat. However, the efficiency of carbon tax is weakened by shifting partial or all tax to consumers and the emission trading scheme is yet simple and easy to implement to the government authority. Therefore, Jotzo and Pezzey [1] conclude that the carbon taxation measure is proved theoretically to be superior to carbon emission trading instrument, whereas the latter is more widely used in practice. This motivates the context in which the Chinese government announced its intent to establish a national carbon trading system in the early 13th Five-Year Plan (2016-2019) [2]. As a first step, the National Development and Reform Commission of China has initiated carbon trading pilots in seven provinces and cities in 2011 and the pilots were operative over the last three years [3]. Each pilot covers a city-Beijing, Shanghai, Tianjin, Shenzhen, and Chongqing-or a province-Guangdong and Hubei.

At the beginning of carbon trading, the government authority needs to set a carbon emission cap, and under the cap, carbon emissions allowed are allocated among emitting entities. To set an emission cap is a very important while difficult task since it is related with energy security, economic sustainability, and climate security. An appropriate allocation rule is a vital component of the carbon trading market, though. It is therefore urgent for the Chinese government to develop the rule in which carbon emission rights are distributed efficiently among participants. There are three alternative allocation rules, varying from full auctioning to full free of charge. In these rules, each entity's actual carbon dioxide emissions must be covered by its emissions allowed. Otherwise, several sanctions will be imposed on it. Hence, we call the carbon trading scheme as the "mandatory reduction." Mandatory reduction has been widely used in 
the European Union and is well recognized by researchers, such as Klepper and Peterson [4], Neuhoff et al. [5], Demailly and Quirion [6], Wang et al. [7], Massetti and Tavoni [8], and Wang et al. $[9,10]$. Mandatory reduction now may be a major market-based instrument that would help China meet its carbon intensity target in a more predictable way [11], and high-level officials began talking openly about the issue. Meanwhile, to encourage enterprises to take part in carbon reduction, environmental exchanges introduce both unilateral and bilateral carbon trading modes by learning from the Clean Development Mechanism and put them into practice. In both modes, the enterprise reduces its carbon emissions freely, and the decrement can be sold to the other enterprises. These two modes in this paper are called the "voluntary reduction." Of course, there are some other reduction measures, such as carbon taxation $[12,13]$, raising of energy prices [14], improving of the ratio of clean energy in energy consumption [15], and developing of carbon capture and storage technology [16]. Although to a large extent these measures are reasonable in theory and feasible in practical usage, they are not the interest of this paper. In this paper, we focus on both the mandatory and voluntary reduction measures.

So far, the mandatory and voluntary reduction measures are two much more popular reduction modes. The question that is of great interest and significance is which mode can meet the reduction target with the minimum cost, which is the key to this paper. After classifying reduction investment ways into three types and splitting the investment duration into two periods, an optimal model is introduced to describe the investment behavior of enterprises. Under the proposed model, we demonstrate the mandatory and voluntary reduction measures in detail. The results obtained in this paper can serve as a theoretical and technical basis for the policy-makings.

This paper is organized as follows. Section 2 presents the basic model. Section 3 discusses the optimal reduction investment behavior of enterprises and its profound implications. Section 4 studies the optimal reduction investment in the mandatory and voluntary reduction measures, respectively. Section 5 uses numerical examples to further explain our findings, and finally, Section 6 presents a brief conclusion. For the clarity of the exposition, we include only the chief results in the main body of the paper. All detailed proofs are placed in Appendix.

\section{The Basic Model}

Theoretically, many pathways can be adopted to reduce carbon emissions in transportation industry, such as the innovation in transportation technology, low carbon technology development, travel time cut, and electric vehicle encouragement [17-19]. In practice, to achieve the carbon reduction target, the following measures were adopted in the Chinese 12th Five-Year Plan (2010-2015): promoting management level, phasing out outdated techniques, speeding up technological innovation, upgrading traditional industries with information technology, and increasing the ratio of clean energy in the energy consumption [20]. Typically, the emission reduction measures of technological innovation and renewable energy were also mentioned in the Outline of the Chinese 13th Five-Year Plan (2016-2020) [21]. In a word, in this paper we classify emission reduction measures into three categories-the technical measure, the clean energy measure, and the management measure.

In terms of the technical measure, the carbon emissions reduction is from two pathways. On one hand, technical progress can help entities cut carbon emissions through improving energy efficiency. On the other hand, technical innovation can help businesses curb carbon emissions by reducing carbon emissions embodied in goods. Roughly speaking, the technical measure involves no changes in the input factor portfolio of production. Different from the technical one, the clean energy measure changes the input factor portfolio of production, reducing carbon emission by replacing the traditional carbon-based energy with clean energy (nuclear energy, solar energy, tidal energy, or wind energy). Notably, improving personnel energy-saving awareness is essential to the management measure.

No matter which measure is used, cost is needed. The technical measure needs research and development (R\&D). $\mathrm{R} \& \mathrm{D}$ cost in this paper is called " $\mathrm{R} \& \mathrm{D}$ investment." When clean energy is used to replace the carbon-based energy, compatible equipment must be installed, which also involves cost. We call this cost "equipment investment." The management measure, trying to reshape personnel's behavior habits, also needs time and material incentives. Cost resulting from such management is called "behavioral investment."

Suppose $N$ enterprises are involved in carbon emission reduction and the investment program can be divided into two periods: the first period spans 2016-2019; the second one is the period in 2020. Such division is used for the following reasons: during 2016-2019, a national carbon trading market in China will be established gradually, while most of the enterprises reduce carbon emission through their own investment, given the carbon emission cap; in 2020, however, when the national carbon trading scheme would have been established, all the enterprises can reduce their carbon emissions by their own investment or cover their actual emissions by buying carbon emission permits to meet the emission cap.

With the condition of no deliberate reduction investment, enterprise $i$ 's BAU (business-as-usual) carbon emissions in the first and second period are denoted as $b_{1 i}$ and $b_{2 i}$, respectively. Correspondingly, if the intended reduction investment rises, the actual carbon emissions from the $i$ th enterprise are denoted by $e_{1 i}$ and $e_{2 i}$, respectively. It is easy to estimate that the decrement in carbon emissions by enterprise $i$ in periods 1 and 2 is, respectively, $b_{1 i}-e_{1 i}$ and $b_{2 i}-e_{2 i}$. Suppose the carbon emission cap by 2020 is $K$; then it is clear that the following inequality must hold:

$$
\sum_{i=1}^{N}\left(e_{1 i}+e_{2 i}\right) \leq K
$$

Furthermore, we suppose that, for each enterprise $i$, its investments spent on R\&D, equipment, and behavior are, respectively, $\left(x_{1 i}, x_{2 i}\right),\left(y_{1 i}, y_{2 i}\right)$, and $\left(z_{1 i}, z_{2 i}\right)$ in periods 1 and 2 .

Since R\&D investment is a long-term program and technical breakthrough is very difficult in short term, as in Kennedy [22], we suppose the carbon reduction of enterprise 
$i$ in the first period is $\alpha_{1 i} x_{1 i}^{1 / 2}$. The carbon reduction of enterprise $i$ in the second period stems from two sources. The first comes from $x_{2 i}$, denoted as $\theta_{2 i} x_{2 i}^{1 / 2}$, while the second comes from $x_{1 i}$, denoted as $\alpha_{2 i} x_{1 i}^{1 / 2}$. Parameters $\alpha_{1 i}, \alpha_{2 i}$, and $\theta_{2 i}$ are nonnegative, indicating the emission reduction efficiency. There is no carbon emission reduction if the parameters are zero. Since R\&D is a long cumulative process, it is reasonable to assume that emission reduction efficiency will be increased with time, which means $\alpha_{2 i} \geq \alpha_{1 i}$. As R\&D investment $x_{2 i}$ is based on some already known facts, thus it can be expected that $\alpha_{2 i} \geq \theta_{2 i} \geq \alpha_{1 i}$.

New equipment needs new skills. It is reasonable to assume that it takes time for employees to be familiar with this new equipment and its operations. Hence, it can be expected that new equipment will operate more efficiently with the improvement of employees' familiarity with them. Let the emission reduction resulting from new equipment be

$$
\beta_{1 i} y_{1 i}^{1 / 2}+\beta_{2 i} y_{1 i}^{1 / 2}+\phi_{2 i} y_{2 i}^{1 / 2},
$$

where $0 \leq \beta_{1 i} \leq \phi_{2 i} \leq \beta_{2 i}$, as in Wang et al. [7]. The remaining emission reduction is attributed to behavioral investment. The reduction of enterprise $i$ in the first period is

$$
b_{1 i}-e_{1 i}-\alpha_{1 i} x_{1 i}^{1 / 2}-\beta_{1 i} y_{1 i}^{1 / 2},
$$

and the reduction in the second period is

$$
b_{2 i}-e_{2 i}-\alpha_{2 i} x_{1 i}^{1 / 2}-\theta_{2 i} x_{2 i}^{1 / 2}-\beta_{2 i} y_{1 i}^{1 / 2}-\phi_{2 i} y_{2 i}^{1 / 2} .
$$

Relative to R\&D and equipment investment, behavior investment results in less emission reduction in absolute sense but higher investment costs in unit reduction for the reason that habits are greatly difficult to reshape. Following Parry and Toman [23], we use the following way to calculate the costs of behavior emission reduction in different periods:

$$
\begin{aligned}
z_{1 i} & =v_{i}\left(b_{1 i}-e_{1 i}-\alpha_{1 i} x_{1 i}^{1 / 2}-\beta_{1 i} y_{1 i}^{1 / 2}\right)^{2}, \\
z_{2 i} & =v_{i}\left(b_{2 i}-e_{2 i}-\alpha_{2 i} x_{1 i}^{1 / 2}-\theta_{2 i} x_{2 i}^{1 / 2}-\beta_{2 i} y_{1 i}^{1 / 2}\right. \\
& \left.-\phi_{2 i} y_{2 i}^{1 / 2}\right)^{2} .
\end{aligned}
$$

Unlike technical emission reduction, behavioral emission reduction does not change too much with time. In this paper, the same parameter $v_{i}$ is used for both periods 1 and 2 .

The parameters, $\alpha_{1 i}, \alpha_{2 i}, \beta_{1 i}, \beta_{2 i}, \theta_{2 i}, \phi_{2 i}$, and $v_{i}$, can be estimated with experiments. To be specific, we can randomly divide the $N$ enterprises into two groups: the experimental group and control group. With the other conditions constant, suppose the $R \& D$ investment of the experimental group is $x_{1 i}$, while the excess emission reductions of the control group in periods 1 and 2 are $\Delta_{1 i}$ and $\Delta_{2 i}$, respectively. The parameters of $\alpha_{1 i}$ and $\alpha_{2 i}$ can be obtained by $\alpha_{1 i}=\Delta_{1 i} /\left(x_{1 i}\right)^{1 / 2}$ and $\alpha_{2 i}=$ $\Delta_{2 i} /\left(x_{1 i}\right)^{1 / 2}$. The same method can be used in the estimation of the other parameters.

Compared with the BAU case, the deliberate mitigation is beneficial to sustainable development and people's health which in turn can save the cost spent on climate management and medical care. The Ministry of Environmental Protection of China had claimed to relate carbon emission reduction to environmental benefits [24]. As the environmental benefits are the same to all enterprises, we denote the average environmental benefits in periods 1 and 2 as $\delta_{1}$ and $\delta_{2}$. Meanwhile, the enterprises have their own incentives to abate carbon emissions. For example, if the enterprises emit less than they are allowed, they can sell their surplus allowances and make a profit. In addition, the enterprises with lower carbon emission have more probability to pass the environmental quality inspection and their products will be more preferred by consumers. Therefore, it is profitable for enterprises to embark on the emission reduction investment. Suppose, per unit of emission reduction, that the average market profits obtained by enterprise $i$ in periods 1 and 2 are, respectively, $\pi_{1 i}$ and $\pi_{2 i}$. Since emission reduction investments are made, respectively, at the beginning of each period, we take the first period as the spot and the second one as the future. Since future investment will be confronted with more uncertainty, we discount the future profit in the spot by $\lambda$ (Dai and Wen [25] and Wen et al. [26, 27] describe the risk measurement). The total profits of the $N$ enterprises are shown as follows:

$$
\sum_{i=1}^{N}\left(\pi_{1 i}+\delta_{1}\right)\left(b_{1 i}-e_{1 i}\right)+\lambda \sum_{i=1}^{N}\left(\pi_{2 i}+\delta_{2}\right)\left(b_{2 i}-e_{2 i}\right) .
$$

In practice, the interbank lending rate can be used as the discount rate. As the enterprises can estimate $\left(b_{1 i}, b_{2 i}\right)$ based on their own historical energy consumption, the decision variables of enterprise $i$ are $\left(x_{1 i}, x_{2 i}, y_{1 i}, y_{2 i}, z_{1 i}, z_{2 i}\right)$ or $\left(x_{1 i}\right.$, $\left.x_{2 i}, y_{1 i}, y_{2 i}, e_{1 i}, e_{2 i}\right)$.

\section{The Optimal Emission Reduction Investment}

To meet the defined carbon emission-abatement target, the optimal problem of minimizing the total investment costs is as the following:

$$
\begin{aligned}
\min _{X, Y, E} \sum_{i=1}^{N} & {\left[x_{1 i}+y_{1 i}+v_{i}\left(b_{1 i}-e_{1 i}-\alpha_{1 i} x_{1 i}^{1 / 2}-\beta_{1 i} y_{1 i}^{1 / 2}\right)^{2}\right]-\sum_{i=1}^{N}\left(\pi_{1 i}+\delta_{1}\right)\left(b_{1 i}-e_{1 i}\right) } \\
& +\lambda\left\{\sum_{i=1}^{N}\left[x_{2 i}+y_{2 i}+v_{i}\left(b_{2 i}-e_{2 i}-\alpha_{2 i} x_{1 i}^{1 / 2}-\theta_{2 i} x_{2 i}^{1 / 2}-\beta_{2 i} y_{1 i}^{1 / 2}-\phi_{2 i} y_{2 i}^{1 / 2}\right)^{2}\right]-\sum_{i=1}^{N}\left(\pi_{2 i}+\delta_{2}\right)\left(b_{2 i}-e_{2 i}\right)\right\}
\end{aligned}
$$

s.t. $\sum_{i=1}^{N}\left(e_{1 i}+e_{2 i}\right) \leq K$ 
where $X=\left(x_{11}, x_{12}, \ldots, x_{1 N}, x_{21}, x_{22}, \ldots, x_{2 N}\right), Y=\left(y_{11}\right.$, $\left.y_{12}, \ldots, y_{1 N}, y_{21}, y_{22}, \ldots, y_{2 N}\right)$, and $E=\left(e_{11}, e_{12}, \ldots, e_{1 N}, e_{21}\right.$, $\left.e_{22}, \ldots, e_{2 N}\right)$.

When $\delta_{1}$ and $\delta_{2}$ are large enough, to save investment costs, the constraint condition in (P1) is not binding; namely, $\sum_{i=1}^{N}\left(e_{1 i}+e_{2 i}\right)<K$. Although the development mode of treatment after pollution is not desirable, the existence of nonbinding constraint may not be possible due to the current state of China. China today is in the process of industrialization and urbanization; the primary task is to improve people's living standard. Relative to physical commodity, clean air is not the first concern in most people's daily life. Thus, parameters $\delta_{1}$ and $\delta_{2}$ cannot be large enough. So we only consider the case of (P1) with the binding constraint. The optimal solution to (P1) is presented as follows:

$$
\begin{aligned}
x_{1 i}^{*} & =\left(\frac{2(B-K)+\left(\delta_{1}+\pi_{1 i}-\lambda\left(\delta_{2}+\pi_{2 i}\right)\right)\left(J_{12}+J_{2}\right)}{2 J} \alpha_{1 i}\right. \\
& \left.+\frac{2(B-K)+\left(\lambda\left(\delta_{2}+\pi_{2 i}\right)-\delta_{1}-\pi_{1 i}\right)\left(J_{1}+J_{12}\right)}{2 J} \alpha_{2 i}\right)^{2} \\
y_{1 i}^{*} & =\left(\frac{2(B-K)+\left(\delta_{1}+\pi_{1 i}-\lambda\left(\delta_{2}+\pi_{2 i}\right)\right)\left(J_{12}+J_{2}\right)}{2 J} \beta_{1 i}\right. \\
& \left.+\frac{2(B-K)+\left(\lambda\left(\delta_{2}+\pi_{2 i}\right)-\delta_{1}-\pi_{1 i}\right)\left(J_{1}+J_{12}\right)}{2 J} \beta_{2 i}\right)^{2} \\
z_{1 i}^{*} & =\frac{1}{v_{i}}\left(\frac{2(B-K)+\left(\delta_{1}+\pi_{1 i}-\lambda\left(\delta_{2}+\pi_{2 i}\right)\right)\left(J_{12}+J_{2}\right)}{2 J}\right)^{2} \\
x_{2 i}^{*} & =\left(\frac{2(B-K)+\left(\lambda\left(\delta_{2}+\pi_{2 i}\right)-\delta_{1}-\pi_{1 i}\right)\left(J_{1}+J_{12}\right)}{2 \lambda J} \theta_{2 i}\right)^{2} \\
y_{2 i}^{*} & =\left(\frac{2(B-K)+\left(\lambda\left(\delta_{2}+\pi_{2 i}\right)-\delta_{1}-\pi_{1 i}\right)\left(J_{1}+J_{12}\right)}{2 \lambda J} \phi_{2 i}\right)^{2} \\
z_{2 i}^{*} & =\frac{1}{v_{i}}\left(\frac{2(B-K)+\left(\lambda\left(\delta_{2}+\pi_{2 i}\right)-\delta_{1}-\pi_{1 i}\right)\left(J_{1}+J_{12}\right)}{2 \lambda J}\right)^{2}, \ldots, N,
\end{aligned}
$$

where $B=\sum_{i=1}^{N}\left(b_{1 i}+b_{2 i}\right), J_{1}=\sum_{i=1}^{N}\left(\alpha_{1 i}^{2}+\beta_{1 i}^{2}+1 / \nu_{i}\right), J_{2}=$ $\sum_{i=1}^{N}\left[\alpha_{2 i}^{2}+\beta_{2 i}^{2}+(1 / \lambda)\left(\theta_{2 i}^{2}+\phi_{2 i}^{2}+1 / \nu_{i}\right)\right], J_{12}=\sum_{i=1}^{N}\left(\alpha_{1 i} \alpha_{2 i}+\right.$ $\left.\beta_{1 i} \beta_{2 i}\right)$, and $J=J_{1}+2 J_{12}+J_{2}$.

The main contribution of model (P1) can be summarized as follows. First, based on the creation of the Chinese carbon trading system, the investment duration of enterprises is divided into two periods, which makes the model be more coincident with the Chinese realization and related findings be more applicable for policy-making. Second, the model here generalizes the one in Wang et al. [7] but is different from it. The model and some results in Wang et al. [7] are just special cases of this paper. Property 1 in Wang et al. [7] is a special case of our model with $x_{2 i}=y_{2 i}=$ $z_{2 i}=e_{2 i}=\pi_{2 i}=\pi_{1 i}=\delta_{2}=0$, for example. Wang et al. [7] focus on measuring and controlling the uncertainty of carbon reduction investment, while this paper mainly examines the difference between the mandatory and voluntary reduction measures. In addition, when enterprise's benefits from emission reduction are taken into account, new findings are obtained-some results are different from and some are even contrary to the corresponding ones in Wang et al. [7].

There are some interesting comparative static analyses which are profound implications for Chinese high-level officials. According to the system of (7), if the carbon reduction budget is increasing (equivalently, the emission cap $K$ becomes small), the enterprise will have to put more investment in $\mathrm{R} \& \mathrm{D}$, equipment, and behavior. The fact that the regional economy in China has a lot of imbalance determines that policymakers indispensably take such imbalance into account when making regional carbon reduction targets. Moreover, the Chinese economy growth now is slowing down; the GDP growth for the first time in 2012 is less than $8 \%$ and the trend is expected to continue. In this macroeconomics situation, tightening emission cap would have great impact on the Chinese economy growth. Therefore, it is necessary to reconsider the Chinese carbon emission target in 2020.

Taking $1 / v_{i}$ as the emission reduction efficiency of behavioral investment, it can be obtained from (7) that the investment level of enterprises is highly related to the efficiency. Specifically, the emission reduction from R\&D and equipment investment in period 1 is well defined in periods 1 and 2. The investment level of $R \& D$ and equipment is the square of weighted sum of emission reduction efficiencies of both periods 1 and 2. The weight depends on the efficiency of the $N$ enterprises. This result is consistent with our intuition: due to the comparative advantage, the government authority will no doubt take into account the difference among enterprises and regions to minimize the emission reduction cost, given the emission reduction target. Furthermore, the question considered in this paper is whether or not the emission reduction target can be achieved in 2020; thus we set the final time point to be 2020 . In this way, the R\&D and equipment investment of enterprise in period 2 is only related to the reduction efficiency of period 2. Actually, that investment in period 2 still has its contribution to emissions reduction after 2020, which should also be taken into consideration when government is making emission reduction policies. Besides, the system of (7) has some implications for emission reduction investment structure. For example, $x_{2 i}: y_{2 i}$ : $z_{2 i}=\theta_{2 i}^{2}: \phi_{2 i}^{2}: 1 / v_{i}$. Finally, if we take no consideration of the difference between spot and future wealth $(\lambda=1)$ and assume the average benefits from emission reduction do not change with time, then behavioral investments in period 1 and period 2 are the same, which is consistent with the fact that the effectiveness of behavioral emission reduction does not change too much with time.

\section{Implementation of the Optimal Investment}

In practice, with lack of government policy guidance, individual enterprise will not take environmental profit into consideration but only the profit from commodities with 
lower carbon emission. In such case, the enterprise's problem on emission reduction investment is presented as follows:

$$
\begin{aligned}
\min _{x_{1 i}, x_{2 i}, y_{1 i}, y_{2 i}, e_{1 i}, e_{2 i}} & x_{1 i}+y_{1 i}+v_{i}\left(b_{1 i}-e_{1 i}-\alpha_{1 i} x_{1 i}^{1 / 2}-\beta_{1 i} y_{1 i}^{1 / 2}\right)^{2}-\pi_{1 i}\left(b_{1 i}-e_{1 i}\right) \\
& +\lambda\left[x_{2 i}+y_{2 i}+v_{i}\left(b_{2 i}-e_{2 i}-\alpha_{2 i} x_{1 i}^{1 / 2}-\theta_{2 i} x_{2 i}^{1 / 2}-\beta_{2 i} y_{1 i}^{1 / 2}-\phi_{2 i} y_{2 i}^{1 / 2}\right)^{2}-\pi_{2 i}\left(b_{2 i}-e_{2 i}\right)\right] .
\end{aligned}
$$

From (P2), the optimal emission reduction investments of enterprise $i$ are

$$
\begin{aligned}
& \bar{x}_{1 i}=\left(\frac{1}{2} \pi_{1 i} \alpha_{1 i}+\frac{1}{2} \lambda \pi_{2 i} \alpha_{2 i}\right)^{2}, \\
& \bar{y}_{1 i}=\left(\frac{1}{2} \pi_{1 i} \beta_{1 i}+\frac{1}{2} \lambda \pi_{2 i} \beta_{2 i}\right)^{2}, \\
& \bar{z}_{1 i}=\frac{1}{v_{i}}\left(\frac{1}{2} \pi_{1 i}\right)^{2}, \\
& \bar{x}_{2 i}=\left(\frac{1}{2} \pi_{2 i} \theta_{2 i}\right)^{2}, \\
& \bar{y}_{2 i}=\left(\frac{1}{2} \pi_{2 i} \phi_{2 i}\right)^{2}, \\
& \bar{z}_{2 i}=\frac{1}{v_{i}}\left(\frac{1}{2} \pi_{2 i}\right)^{2} .
\end{aligned}
$$

From the perspective of minimizing cost, the optimal solution (8) shows that the deliberate emission reduction investment of the enterprise is related to neither environmental profit nor emission budget. Comparing (7) with (8), we find that, in case of $\delta_{1} \neq \lambda \delta_{2}$, the investment behavior of individual enterprise will deviate from the optimal level in the absence of policy guidance. An interesting and significant question is what policies can help individual enterprise to implement the optimal emission reduction investment. In the remaining passage, we will discuss this question in both the mandatory and voluntary reduction measures.

4.1. Mandatory Reduction Measure. The mandatory reduction measure attempts to set emission allowance $K$ among enterprises, with allowances capped in accordance with the defined emissions reduction target. Each enterprise gets its initial carbon emission permits through either free of charge or auction. The enterprises will be punished if their actual carbon emissions are more than emissions allowed. Because in the mandatory reduction measure enterprises pay for their actual carbon emissions (e.g., carbon tax), they will determine their investment levels at the beginning of each period. Assume the carbon price per unit in period 1 is $p_{1}$ and $p_{2}$ in period 2; then the investment decision problem of enterprise $i$ is

$$
\begin{aligned}
\min _{x_{1 i}, x_{2 i}, y_{1 i}, y_{2 i}, e_{1 i}, e_{2 i}} & x_{1 i}+y_{1 i}+v_{i}\left(b_{1 i}-e_{1 i}-\alpha_{1 i} x_{1 i}^{1 / 2}-\beta_{1 i} y_{1 i}^{1 / 2}\right)^{2}+p_{1} e_{1 i}-\pi_{1 i}\left(b_{1 i}-e_{1 i}\right) \\
& +\lambda\left[x_{2 i}+y_{2 i}+v_{i}\left(b_{2 i}-e_{2 i}-\alpha_{2 i} x_{1 i}^{1 / 2}-\theta_{2 i} x_{2 i}^{1 / 2}-\beta_{2 i} y_{1 i}^{1 / 2}-\phi_{2 i} y_{2 i}^{1 / 2}\right)^{2}+p_{2} e_{2 i}-\pi_{2 i}\left(b_{2 i}-e_{2 i}\right)\right] .
\end{aligned}
$$

At this moment, the optimal investment decision of enterprise $i$ is expressed as

$$
\begin{aligned}
& \tilde{x}_{1 i}=\left(\frac{p_{1}+\pi_{1 i}}{2} \alpha_{1 i}+\frac{\lambda\left(p_{2}+\pi_{2 i}\right)}{2} \alpha_{2 i}\right)^{2}, \\
& \tilde{y}_{1 i}=\left(\frac{p_{1}+\pi_{1 i}}{2} \beta_{1 i}+\frac{\lambda\left(p_{2}+\pi_{2 i}\right)}{2} \beta_{2 i}\right)^{2}, \\
& \tilde{z}_{1 i}=\frac{1}{v_{i}}\left(\frac{p_{1}+\pi_{1 i}}{2}\right)^{2}, \\
& \tilde{x}_{2 i}=\left(\frac{p_{2}+\pi_{2 i}}{2} \theta_{2 i}\right)^{2}, \\
& \tilde{y}_{2 i}=\left(\frac{p_{2}+\pi_{2 i}}{2} \phi_{2 i}\right)^{2}, \\
& \tilde{z}_{2 i}=\frac{1}{v_{i}}\left(\frac{p_{2}+\pi_{2 i}}{2}\right)^{2} .
\end{aligned}
$$

If enterprises obtain the emission permits for free, namely, $p_{1}=p_{2}=0$, we have the following property.

Property 1. If enterprises get carbon emission permits for free and $\delta_{1} \neq \lambda \delta_{2}$, then the emission reduction investment of enterprises deviates from the optimal level.

Free distribution is easy to implement and the initial emission permits can be obtained by combing grandfathering principle and benchmarking principle. For production process hard to improve, initial allowances can be determined by historical emissions data (grandfathering principle). For production process easy to improve, the enterprise emitting the lowest carbon is selected as a benchmark; the allowances of other enterprises are determined by the benchmark multiplied by their scale (benchmarking principle). For enterprises with great reduction potential, the allowance is initially assigned by grandfathering and then determined by 
benchmarking year by year. Free distribution approach takes into account not only the historical contribution of enterprise but also the competitive advantages among enterprises.

If enterprises get their permits through auction or bidding, then $p_{1}>0$ and $p_{2}>0$; in such case, the relation between emission reduction investment of individual enterprise and the optimal level can be summarized as Property 2.

Property 2. If enterprises get their carbon emission permits through auction, the emission reduction investment of enterprise $i$ is equal to the optimal level only when

$$
\begin{aligned}
p_{1 i}= & \frac{2(B-K)+\left(\delta_{1}+\pi_{1 i}-\lambda\left(\delta_{2}+\pi_{2 i}\right)\right)\left(J_{12}+J_{2}\right)}{J} \\
& -\pi_{1 i} \\
p_{2 i}= & \frac{2(B-K)+\left(\lambda\left(\delta_{2}+\pi_{2 i}\right)-\delta_{1}-\pi_{1 i}\right)\left(J_{1}+J_{12}\right)}{\lambda J} \\
& -\pi_{2 i} .
\end{aligned}
$$

Otherwise, the investment of individual enterprise deviates from the optimal level in either period 1 or period 2 or even both.

It is truth that enterprises need to spend time on adapting the process from free of charge to auction. So some researchers suggest using free of charge at the beginning and, in the following, increasing gradually the ratio of auction. Suppose free of charge is used in period 1 and auction in period 2 ; then we have $p_{1}=0, p_{2}>0$.

Property 3. If enterprises get the carbon emission permits in period 1 through free of charge and in period 2 by auction and if

$$
\begin{aligned}
p_{2 i}= & \frac{2(B-K)+\left(\lambda\left(\delta_{2}+\pi_{2 i}\right)-\delta_{1}-\pi_{1 i}\right)\left(J_{1}+J_{12}\right)}{\lambda J} \\
& -\pi_{2 i}>\frac{\lambda \delta_{2}-\delta_{1}}{\lambda}
\end{aligned}
$$

then the investment of enterprise $i$ in period 1 is lower than the optimal level and optimal in period 2. In this case, the total emission reduction investment of the $N$ enterprises is lower than the optimal one, whereas the total carbon emissions are larger than $K$. If

$$
\begin{aligned}
p_{2 i}= & \frac{2(B-K)+\left(\lambda\left(\delta_{2}+\pi_{2 i}\right)-\delta_{1}-\pi_{1 i}\right)\left(J_{1}+J_{12}\right)}{\lambda J} \\
& -\pi_{2 i}<\frac{\lambda \delta_{2}-\delta_{1}}{\lambda}
\end{aligned}
$$

then the investment of enterprise $i$ in period 1 is higher than the optimal level and optimal in period 2 . If

$$
\begin{gathered}
p_{2 i}=\frac{2(B-K)+\left(\lambda\left(\delta_{2}+\pi_{2 i}\right)-\delta_{1}-\pi_{1 i}\right)\left(J_{1}+J_{12}\right)}{\lambda J} \\
-\pi_{2 i}=\frac{\lambda \delta_{2}-\delta_{1}}{\lambda}
\end{gathered}
$$

the investment of enterprise $i$ is optimal. If

$$
\begin{aligned}
p_{2 i} \neq & \frac{2(B-K)+\left(\lambda\left(\delta_{2}+\pi_{2 i}\right)-\delta_{1}-\pi_{1 i}\right)\left(J_{1}+J_{12}\right)}{\lambda J} \\
& -\pi_{2 i}
\end{aligned}
$$

the investment of enterprise $i$ in period 2 deviates from the optimal level.

4.2. Voluntary Reduction Measure. Due to economic and technical difference among regions, the Chinese government needs to adopt different emission reduction mechanisms to balance the difference. Except for the mandatory reduction measure, the Chinese government also introduces unilateral and bilateral carbon trading.

Unilateral and bilateral carbon trading modes first appear in Kyoto Protocol. In unilateral mode, enterprises reduce voluntarily their carbon emissions. The decrement relative to $\mathrm{BAU}, b_{i}-e_{i}$, once certificated by the third party, can be sold to other enterprises in need. In bilateral mode, enterprises ready for emission reduction negotiate with the counter parties ready to purchase emissions allowed in terms of trading quantity and price. On the date of delivery, the seller sells its emission reduction of $b_{i}-e_{i}$ to the buyer at the negotiated price.

According to the trading mechanism, suppose the emission reduction of enterprise $i$, in unilateral case, is $b_{1 i}+b_{2 i}-$ $e_{1 i}-e_{2 i}$, and the trading price is $w$; then minimum problem for enterprise $i$ is

$$
\begin{aligned}
\min _{x_{1 i}, x_{2 i}, y_{1 i}, y_{2 i}, e_{1 i}, e_{2 i}} & x_{1 i}+y_{1 i}+v_{i}\left(b_{1 i}-e_{1 i}-\alpha_{1 i} x_{1 i}^{1 / 2}-\beta_{1 i} y_{1 i}^{1 / 2}\right)^{2}-\pi_{1 i}\left(b_{1 i}-e_{1 i}\right) \\
& +\lambda\left[x_{2 i}+y_{2 i}+v_{i}\left(b_{2 i}-e_{2 i}-\alpha_{2 i} x_{1 i}^{1 / 2}-\theta_{2 i} x_{2 i}^{1 / 2}-\beta_{2 i} y_{1 i}^{1 / 2}-\phi_{2 i} y_{2 i}^{1 / 2}\right)^{2}-w\left(b_{1 i}+b_{2 i}-e_{1 i}-e_{2 i}\right)-\pi_{2 i}\left(b_{2 i}-e_{2 i}\right)\right] .
\end{aligned}
$$

Based on (P4), we discuss whether or not the unilateral trading mode can bring the optimal emission reduction investment.
Property 4. Whatever the trading price $w$ is, the emission reduction investment of individual enterprise is never optimal in unilateral mode if $\delta_{1} \neq \lambda \delta_{2}$. In case of $\delta_{1}=\lambda \delta_{2}$, the 
government can guide the investment of individual enterprise to the optimal result by setting trading price

$$
w=\frac{2(B-K)-\pi_{1 i}\left(J_{1}+J_{12}\right)-\lambda \pi_{2 i}\left(J_{12}+J_{2}\right)}{\lambda J} .
$$

Unilateral trading mode stimulates the enterprises to take voluntary emission reduction investment, but the trading price is negotiated among enterprises. Enterprises involved in voluntary reduction would adjust their investment level by the negotiated prices in order to minimize their emission reduction costs.

Bilateral trading mode might be a good alternative if the enterprises do not have enough capital to make investment. In the bilateral trading mechanism, we assume the trading price in period 1 is $w_{1}$ and the trading price in period 2 $w_{2}$; then the profit of enterprise $i$ in period 1 resulting from investment is $\left(w_{1}+\pi_{1 i}\right)\left(b_{1 i}-e_{1 i}\right)$ and the profit of period 2 is $\left(w_{2}+\pi_{2 i}\right)\left(b_{2 i}-e_{2 i}\right)$. Therefore, the minimum problem of enterprise $i$ in bilateral mode is

$$
\begin{aligned}
\min _{x_{1 i}, x_{2 i}, y_{1 i}, y_{2 i}, e_{1 i}, e_{2 i}} & x_{1 i}+y_{1 i}+v_{i}\left(b_{1 i}-e_{1 i}-\alpha_{1 i} x_{1 i}^{1 / 2}-\beta_{1 i} y_{1 i}^{1 / 2}\right)^{2}-\left(w_{1}+\pi_{1 i}\right)\left(b_{1 i}-e_{1 i}\right) \\
& +\lambda\left[x_{2 i}+y_{2 i}+v_{i}\left(b_{2 i}-e_{2 i}-\alpha_{2 i} x_{1 i}^{1 / 2}-\theta_{2 i} x_{2 i}^{1 / 2}-\beta_{2 i} y_{1 i}^{1 / 2}-\phi_{2 i} y_{2 i}^{1 / 2}\right)^{2}-\left(w_{2}+\pi_{2 i}\right)\left(b_{2 i}-e_{2 i}\right)\right] .
\end{aligned}
$$

Solving the minimum problem of (P5), we have Property 5.

Property 5. For the case of $\delta_{1}=\lambda \delta_{2}$, in bilateral trading mode the government can guide the emission reduction investment of individual enterprise to the optimal level if the trading prices are settled as follows:

$$
\begin{aligned}
w_{1} & =\lambda w_{2} \\
& =\frac{2(B-K)-\pi_{1 i}\left(J_{1}+J_{12}\right)-\lambda \pi_{2 i}\left(J_{12}+J_{2}\right)}{J} .
\end{aligned}
$$

In case of $\delta_{1} \neq \lambda \delta_{2}$, the emission reduction investment of individual enterprise is consistent with the optimal level only if

$$
\begin{aligned}
w_{1}= & \frac{2(B-K)+\left(\delta_{1}+\pi_{1 i}-\lambda\left(\delta_{2}+\pi_{2 i}\right)\right)\left(J_{12}+J_{2}\right)}{J} \\
& -\pi_{1 i}, \\
w_{2}= & \frac{2(B-K)+\left(\lambda\left(\delta_{2}+\pi_{2 i}\right)-\delta_{1}-\pi_{1 i}\right)\left(J_{1}+J_{12}\right)}{\lambda J} \\
& -\pi_{2 i} .
\end{aligned}
$$

Otherwise, the emission reduction investment of individual enterprise deviates from the optimal level.

Regardless of the time value of wealth $(\lambda=1)$, if environmental profit and mitigation market profit in periods 1 and 2 are the same and the government guides the trading by setting the negotiating price at $2(B-K) / J$, then bilateral mode can result in the optimal investment level. In bilateral mode, if one side dominates the other by setting too high or too low prices, the emission reduction investment of individual enterprise still deviates from the optimal level even if there is government guidance.

Since there is uncertainty in future investment, future wealth will usually be discounted $(0<\lambda<1)$. Therefore, in bilateral mode we should get the prices under control in both periods 1 and 2 to lower down the deviation of individual emission reduction investment from the optimal level. We also have to take into consideration the time value effect, the emission reduction budget, and the reduction effectiveness of different investment pathways.

\section{A Case Study}

As the carbon emission data of enterprises is not available, we only do numerical analysis to examine the sensitivity of optimal investment to parameters and to investigate the deviation degree of individual investment from the optimal level in the mandatory and voluntary reduction measures.

For simplicity, this paper only considers the case of two enterprises $(N=2)$ with the same efficiency. To examine the sensitivity of the optimal investment to parameters, we set the benchmark, where $b_{1}=b_{2}=250, K=800, \alpha_{1}=\beta_{1}=1$, $\alpha_{2}=\beta_{2}=3, \theta_{2}=\phi_{2}=2, v=1 / 2, \delta_{1}=4, \delta_{2}=5, \pi_{1}=$ $\pi_{2}=1, \lambda=2 / 3, B-K=200, J_{1}=8, J_{2}=66, J_{12}=12$, and $J=98$. By (7), the optimal solutions in the benchmark are $x_{1}^{*}=y_{1}^{*}=68.15, z_{1}^{*}=11.90, x_{2}^{*}=y_{2}^{*}=33.83$, and $z_{2}^{*}=$ 16.91. In Table 1, the optimal investment changes are shown relative to the benchmark, when either of emission budget, efficiency, environmental profit, market profit, and discount factor changes by 10 per cent.

Numbers in each column indicate how the optimal investment changes relative to the benchmark when either one of these parameters changes by 10 per cent. The results in Table 1 show that the effect of the emission budget on investment is the most significant. When the budget is lowered down by 10 per cent, enterprises have to put more investment in $\mathrm{R} \& \mathrm{D}$, equipment, and behavior emission reduction and the investment in the second period will be doubled.

When there is improvement in efficiency of any emission reduction pathway, the investment in the corresponding pathway in both periods will adjust until new equilibrium. However, the investment in period 1 is more sensitive to efficiency than the investment in period 2 (see rows 3-5 in Table 1). The reason is that the emission reduction efficiency improves with time; therefore the change degree of the investment in period 2 is larger than that in period 1. 
TABLE 1: Sensitivity degree of the optimal investment to parameters.

\begin{tabular}{|c|c|c|c|c|c|c|}
\hline & $\Delta x_{1} / x_{1}^{*}$ & $\Delta y_{1} / y_{1}^{*}$ & $\Delta z_{1} / z_{1}^{*}$ & $\Delta x_{2} / x_{2}^{*}$ & $\Delta y_{2} / y_{2}^{*}$ & $\Delta z_{2} / z_{2}^{*}$ \\
\hline$\Delta K / K=-10 \%$ & $94.76 \%$ & $94.76 \%$ & $78.15 \%$ & $101.94 \%$ & $101.94 \%$ & $101.94 \%$ \\
\hline$\Delta \alpha_{1} / \alpha_{1}=10 \%$ & $2.28 \%$ & $-3.52 \%$ & $-2.98 \%$ & $-3.74 \%$ & $-3.74 \%$ & $-3.74 \%$ \\
\hline$\Delta \alpha_{2} / \alpha_{2}=10 \%$ & $4.06 \%$ & $-9.15 \%$ & $-7.77 \%$ & $-9.72 \%$ & $-9.72 \%$ & $-9.72 \%$ \\
\hline$\Delta \theta_{2} / \theta_{2}=10 \%$ & $-4.65 \%$ & $-4.65 \%$ & $-3.95 \%$ & $15.01 \%$ & $-4.95 \%$ & $-4.95 \%$ \\
\hline$\Delta \delta_{1} / \delta_{1}=10 \%$ & $0.89 \%$ & $0.89 \%$ & $13.48 \%$ & $-4.17 \%$ & $-4.17 \%$ & $-4.17 \%$ \\
\hline$\Delta \delta_{2} / \delta_{2}=10 \%$ & $-0.74 \%$ & $-0.74 \%$ & $-10.58 \%$ & $3.54 \%$ & $3.54 \%$ & $3.54 \%$ \\
\hline$\Delta \pi_{1} / \pi_{1}=10 \%$ & $0.22 \%$ & $0.22 \%$ & $3.29 \%$ & $-1.05 \%$ & $-1.05 \%$ & $-1.05 \%$ \\
\hline$\Delta \pi_{2} / \pi_{2}=10 \%$ & $-0.15 \%$ & $-0.15 \%$ & $-2.16 \%$ & $0.70 \%$ & $0.70 \%$ & $0.70 \%$ \\
\hline$\Delta \lambda / \lambda=-10 \%$ & $-5.09 \%$ & $-5.09 \%$ & $8.09 \%$ & $10.66 \%$ & $10.66 \%$ & $10.66 \%$ \\
\hline
\end{tabular}

TABLE 2: Deviations from optimal investment under free of charge.

\begin{tabular}{cccccccc}
\hline$\delta_{2}$ & $\delta_{1}-\lambda \delta_{2}$ & $\Delta x_{1}$ & $\Delta y_{1}$ & $\Delta z_{1}$ & $\Delta x_{2}$ & $\Delta y_{2}$ & $\Delta z_{2}$ \\
\hline 5 & 0.67 & -65.90 & -65.90 & -11.40 & -32.83 & -32.83 & -16.41 \\
6 & 0 & -64.90 & -64.90 & -8.95 & -35.25 & -35.25 & -17.62 \\
7 & -0.67 & -63.89 & -63.89 & -6.78 & -37.74 & -37.74 & -18.87 \\
\hline
\end{tabular}

TABLE 3: Deviations from optimal investment under auction.

\begin{tabular}{|c|c|c|c|c|c|c|c|}
\hline$p_{1 i}$ & $p_{2 i}$ & $\Delta x_{1}$ & $\Delta y_{1}$ & $\Delta z_{1}$ & $\Delta x_{2}$ & $\Delta y_{2}$ & $\Delta z_{2}$ \\
\hline 3.88 & 4.82 & 0 & 0 & 0 & 0 & 0 & 0 \\
\hline 3.88 & 4.33 & -7.77 & -7.77 & -0.01 & -5.42 & -5.42 & -2.71 \\
\hline 3.88 & 5.30 & 8.24 & 8.24 & 0.01 & 5.86 & 5.86 & 2.93 \\
\hline 3.49 & 4.82 & -3.10 & -3.10 & -1.82 & 0.04 & 0.04 & 0.02 \\
\hline 4.27 & 4.82 & 3.34 & 3.34 & 1.99 & 0.04 & 0.04 & 0.02 \\
\hline 3.49 & 4.33 & -10.70 & -10.70 & -1.82 & -5.37 & -5.37 & -2.69 \\
\hline 4.27 & 5.30 & 11.61 & 11.61 & 1.97 & 5.83 & 5.83 & 2.92 \\
\hline
\end{tabular}

Since all the enterprise benefits from the climate improvement, the increment in environmental profit will have an incentive to the investment. Once the market profit from emission reduction increases, the enterprises tempted by profit will change their investment way by putting more resources into emissions reduction; thus the investment is also increasing. In our numerical example, since the environmental profit is assumed to be strictly larger than the market profit, the investment is more sensitive to environmental profit relative to the market profit.

Because the effectiveness of R\&D and equipment investment is reflected in both periods 1 and 2 and the effectiveness in period 2 is better than in period 1, enterprises, when facing future uncertainties, will readjust their capital allocation between these two periods by lowering down the investment in period 1 and upgrading the investment in period 2. A glimpse of columns 5 and 8 in Table 1 shows that behavioral emission reduction is more sensitive to profit than to effectiveness. The reason is that the effectiveness of behavioral emission reduction does not change with time, which thus makes the sensitivity of behavioral investment to effectiveness almost zero.

Table 2 reports the deviations of individual enterprise's investment from the optimal level under free of charge when $\delta_{2}$ takes changes. The results in Table 2 show that when $\delta_{1}-\lambda \delta_{2}$ decreases, the deviation in period 1 is lowering down, while the deviation in period 2 is increasing. The main reason is that the change in $\delta_{1}-\lambda \delta_{2}$ results from the change in $\delta_{2}$. By the results in Table 1 , the investment in period 2 is more sensitive to change in $\delta_{2}$ relative to that in period 1 . Also it can be observed from Table 2 that $\delta_{1}-\lambda \delta_{2} \neq 0$ is not a sufficient condition in the free distribution mode.

In the benchmark, (9) implies that individual enterprise's investment under auction is just the optimal level at $p_{1 i}=$ 3.88 and $p_{2 i}=4.82$. When $p_{1 i}$ and $p_{2 i}$ take other values, the deviation of individual enterprise's investment from the optimal level is reported in Table 3 . As can be observed from Table 3 the deviation is more sensitive to $p_{2 i}$.

Under free-auction combining mode, more strict constraints should be put on auction price $p_{2 i}$ for individual investment to be optimal. In the benchmark, the investment of individual enterprise in period 2 is optimal only when $p_{2 i}=4.82$; the individual investment in period 1 is less than the optimal level with $\Delta x_{1}=\Delta y_{1}=-28.25, \Delta z_{1}=-11.40$. In case $\delta_{2}=18, p_{2 i}=7.44$, and the other parameters remain constant, the investment of individual enterprise in period 2 remains optimal, while that in period 1 is larger than the optimal level with $\Delta x_{1}=\Delta y_{1}=24.81$ and $\Delta z_{1}=1.54$. The deviation from the optimal level in period 2 is presented in Table 4 when $p_{2 i}$ takes other values. 
TABLE 4: Deviations from optimal investment under combining mode.

\begin{tabular}{ccccc}
\hline$\delta_{2}$ & $p_{2 i}$ & $\Delta x_{2}$ & $\Delta y_{2}$ & $\Delta z_{2}$ \\
\hline \multirow{2}{*}{5} & 4 & -8.83 & -8.83 & -4.41 \\
& 5 & 2.17 & 2.17 & 1.09 \\
\hline \multirow{2}{*}{18} & 5.02 & -35.49 & -35.49 & -17.75 \\
& 8 & 9.63 & 9.63 & 4.81 \\
\hline
\end{tabular}

Table 5 presents the deviation in the case of unilateral trading mode when $\delta_{1}-\lambda \delta_{2}$ changes. We change $\delta_{1}-\lambda \delta_{2}$ by giving $\delta_{2}$ different values.

The results in Table 5 show that the investment of individual enterprise can be adjusted to the optimal level by setting trading price $w=5.02$ only if $\delta_{1}-\lambda \delta_{2}=0$. The investment of individual enterprise in periods 1 and 2 deviates from the optimal level as long as $\delta_{1}-\lambda \delta_{2} \neq 0$.

Similar to the unilateral trading mode, if $\delta_{2}=6\left(\delta_{1}-\right.$ $\left.\lambda \delta_{2}=0\right)$, the investment of individual enterprise in bilateral trading is consistent with the optimal level only when $w_{1}=$ 3.35 and $w_{2}=5.02$; if $\delta_{2}=5\left(\delta_{1}-\lambda \delta_{2}=2 / 3\right)$, the investment of individual enterprise in bilateral trading is optimal only when $w_{1}=3.87$ and $w_{2}=4.81$; if $\delta_{2}=7\left(\delta_{1}-\lambda \delta_{2}=-2 / 3\right)$, the individual investment of enterprise in bilateral trading is optimal only when $w_{1}=2.82$ and $w_{2}=5.22$.

\section{A Brief Conclusion}

Realizing that greenhouse gas emissions, climate change, and sustainable economic development are tightly interlinked, the Chinese government developed an ambitious target of carbon emissions reduction by 2020. Maybe the most important issue today is how to achieve the target among emitting enterprises, which is of great interest to Chinese high-level officials. Such concern stems primarily from two realizations: firstly that emitting enterprises must find efficient emission reduction pathways and try best to minimize the associated investment costs, irrespective of what emission cap is, because it is the only way for enterprises to survive; secondly that policy-making focuses on the emission permits' distribution mechanism. There are several alternative allocation patterns used in practice up to now, such as free of charge, auction, unilateral trading, and bilateral trading. The question is how China will assign the emission permits to minimize emission reduction investments, when confronted with the practical and political problems. To answer these questions, this paper establishes the optimal model concerning emission reduction investment actions with the emission cap and examines the profound implications from the viewpoint of efficiency, emission cap, and investment. The finding is that the above four allocation formats fail to achieve the optimal investment level in the absence of governmental policy guidance. Furthermore, trading price is vital to modify the deviation of individual enterprise's investment from the optimal one.

\section{Appendix}

Solutions to (P1). Construct the following Lagrange function:

$$
\begin{aligned}
& L(X, Y, E, \mu)=\sum_{i=1}^{N}\left[x_{1 i}+y_{1 i}+v_{i}\left(b_{1 i}-e_{1 i}-\alpha_{1 i} x_{1 i}^{1 / 2}\right.\right. \\
& \left.\left.\quad-\beta_{1 i} y_{1 i}^{1 / 2}\right)^{2}\right]-\sum_{i=1}^{N}\left(\pi_{1 i}+\delta_{1}\right)\left(b_{1 i}-e_{1 i}\right)+\lambda\left\{\sum _ { i = 1 } ^ { N } \left[x_{2 i}\right.\right. \\
& \quad+y_{2 i} \\
& \left.\quad+v_{i}\left(b_{2 i}-e_{2 i}-\alpha_{2 i} x_{1 i}^{1 / 2}-\theta_{2 i} x_{2 i}^{1 / 2}-\beta_{2 i} y_{1 i}^{1 / 2}-\phi_{2 i} y_{2 i}^{1 / 2}\right)^{2}\right] \\
& \left.\quad-\sum_{i=1}^{N}\left(\pi_{2 i}+\delta_{2}\right)\left(b_{2 i}-e_{2 i}\right)\right\}-\mu\left(K-\sum_{i=1}^{N}\left(e_{1 i}+e_{2 i}\right)\right)
\end{aligned}
$$

where $\mu$ is Lagrange multiplier. Taking partial derivatives of (A.1) with respect to $X, Y, E$, and $\mu$ yields

$$
\begin{aligned}
& 1-v_{i}\left[\alpha_{1 i}\left(b_{1 i}-e_{1 i}-\alpha_{1 i} x_{1 i}^{1 / 2}-\beta_{1 i} y_{1 i}^{1 / 2}\right)+\lambda \alpha_{2 i}\left(b_{2 i}\right.\right. \\
& \left.\left.-e_{2 i}-\alpha_{2 i} x_{1 i}^{1 / 2}-\theta_{2 i} x_{2 i}^{1 / 2}-\beta_{2 i} y_{1 i}^{1 / 2}-\phi_{2 i} y_{2 i}^{1 / 2}\right)\right] \\
& \cdot x_{1 i}^{-1 / 2}=0 \text {, } \\
& 1-v_{i}\left[\beta_{1 i}\left(b_{1 i}-e_{1 i}-\alpha_{1 i} x_{1 i}^{1 / 2}-\beta_{1 i} y_{1 i}^{1 / 2}\right)+\lambda \beta_{2 i}\left(b_{2 i}\right.\right. \\
& \left.\left.-e_{2 i}-\alpha_{2 i} x_{1 i}^{1 / 2}-\theta_{2 i} x_{2 i}^{1 / 2}-\beta_{2 i} y_{1 i}^{1 / 2}-\phi_{2 i} y_{2 i}^{1 / 2}\right)\right] \\
& y_{1 i}^{-1 / 2}=0 \text {, } \\
& 1-\theta_{2 i} \nu_{i}\left(b_{2 i}-e_{2 i}-\alpha_{2 i} x_{1 i}^{1 / 2}-\theta_{2 i} x_{2 i}^{1 / 2}-\beta_{2 i} y_{1 i}^{1 / 2}\right. \\
& \left.-\phi_{2 i} y_{2 i}^{1 / 2}\right) x_{2 i}^{-1 / 2}=0 \\
& 1-\phi_{2 i} \nu_{i}\left(b_{2 i}-e_{2 i}-\alpha_{2 i} x_{1 i}^{1 / 2}-\theta_{2 i} x_{2 i}^{1 / 2}-\beta_{2 i} y_{1 i}^{1 / 2}\right. \\
& \left.-\phi_{2 i} y_{2 i}^{1 / 2}\right) y_{2 i}^{-1 / 2}=0 \\
& \delta_{1}+\pi_{1 i}+\mu-2 v_{i}\left(b_{1 i}-e_{1 i}-\alpha_{1 i} x_{1 i}^{1 / 2}-\beta_{1 i} y_{1 i}^{1 / 2}\right)=0, \\
& \lambda\left(\delta_{2}+\pi_{2 i}\right)+\mu-2 \lambda v_{i}\left(b_{2 i}-e_{2 i}-\alpha_{2 i} x_{1 i}^{1 / 2}-\theta_{2 i} x_{2 i}^{1 / 2}\right. \\
& \left.-\beta_{2 i} y_{1 i}^{1 / 2}-\phi_{2 i} y_{2 i}^{1 / 2}\right)=0 \\
& K-\sum_{i=1}^{N}\left(e_{1 i}+e_{2 i}\right)=0 .
\end{aligned}
$$

Solving (A.2) yields (7). Equation (7) is the only necessary condition for (P1) to reach its minimum value. In the following, we prove that (7) is indeed optimal to (P1).

Let $F_{1 i}\left(x_{1 i}, y_{1 i}, e_{1 i}\right)=b_{1 i}-e_{1 i}-\alpha_{1 i} x_{1 i}^{1 / 2}-\beta_{1 i} y_{1 i}^{1 / 2} ;$ the Hessian matrix of $F_{1 i}\left(x_{1 i}, y_{1 i}, e_{1 i}\right)$ is

$$
D^{2} F_{1 i}\left(x_{1 i}, y_{1 i}, e_{1 i}\right)=\left[\begin{array}{ccc}
\frac{1}{4} \alpha_{1 i} x_{1 i}^{-3 / 2} & 0 & 0 \\
0 & \frac{1}{4} \beta_{1 i} y_{1 i}^{-3 / 2} & 0 \\
0 & 0 & 0
\end{array}\right] \text {. }
$$


TABLE 5: Deviations from optimal investment in unilateral trading mode.

\begin{tabular}{|c|c|c|c|c|c|c|c|c|}
\hline$\delta_{2}$ & $\delta_{1}-\lambda \delta_{2}$ & $w$ & $\Delta x_{1}$ & $\Delta y_{1}$ & $\Delta z_{1}$ & $\Delta x_{2}$ & $\Delta y_{2}$ & $\Delta z_{2}$ \\
\hline & & 4.52 & -11.53 & -11.53 & -3.84 & -3.38 & -3.38 & -1.69 \\
\hline \multirow[t]{3}{*}{5} & $2 / 3$ & 5.02 & -1.01 & -1.01 & -2.45 & 2.42 & 2.42 & 1.21 \\
\hline & & 5.52 & 10.41 & 10.41 & -0.94 & 8.71 & 8.71 & 4.36 \\
\hline & & 4.52 & -10.52 & -10.52 & -1.40 & -5.79 & -5.79 & -2.90 \\
\hline \multirow[t]{3}{*}{6} & 0 & 5.02 & 0 & 0 & 0 & 0 & 0 & 0 \\
\hline & & 5.52 & 11.42 & 11.42 & 1.51 & 6.30 & 6.30 & 3.15 \\
\hline & & 4.52 & -9.52 & -9.52 & 0.77 & -8.29 & -8.29 & -4.15 \\
\hline \multirow[t]{2}{*}{7} & $-2 / 3$ & 5.02 & 1.00 & 1.00 & 2.17 & -2.50 & -2.50 & -1.25 \\
\hline & & 5.52 & 12.42 & 12.42 & 3.68 & 3.80 & 3.80 & 1.90 \\
\hline
\end{tabular}

Obviously, $D^{2} F_{1 i}\left(x_{1 i}, y_{1 i}, e_{1 i}\right)$ is a positive semidefinite matrix. So the function

$$
\begin{gathered}
\sum_{i=1}^{N}\left[x_{1 i}+y_{1 i}+v_{i}\left(F_{1 i}\left(x_{1 i}, y_{1 i}, e_{1 i}\right)\right)^{2}\right] \\
-\sum_{i=1}^{N}\left(\delta_{1}+\pi_{1 i}\right)\left(b_{1 i}-e_{1 i}\right)
\end{gathered}
$$

is convex. Further,

$$
\begin{aligned}
& \sum_{i=1}^{N}\left[x_{2 i}+y_{2 i}+v_{i}\left(F_{2 i}\left(x_{1 i}, x_{2 i}, y_{1 i}, y_{2 i}, e_{2 i}\right)\right)^{2}\right] \\
& \quad-\sum_{i=1}^{N}\left(\delta_{2}+\pi_{2 i}\right)\left(b_{2 i}-e_{2 i}\right)
\end{aligned}
$$

is also convex, where $F_{2 i}\left(x_{1 i}, x_{2 i}, y_{1 i}, y_{2 i}, e_{2 i}\right)=b_{2 i}-e_{2 i}-$ $\alpha_{2 i} x_{1 i}^{1 / 2}-\theta_{2 i} x_{2 i}^{1 / 2}-\beta_{2 i} y_{1 i}^{1 / 2}-\phi_{2 i} y_{2 i}^{1 / 2}$. Therefore, the objective function in (P1) is a convex function. Since the constraint set in (P1) is bounded and closed, there exists optimal solution. For a convex function, (7) is the unique optimal solution to (P1).

Solutions to (P2). Equation (8) can be obtained by calculating the partial derivatives of objective function with respect to $x_{1 i}, x_{2 i}, y_{1 i}, y_{2 i}, e_{1 i}$, and $e_{2 i}$ and setting their values equal to 0 . Similar to (P1), the sufficiency condition of (8) can be proved.

Proof of Property 1. Equation (9) is degenerated to (8) if both $p_{1}$ and $p_{2}$ take value 0 . The result can be obtained by comparing (8) with (7).

Proof of Property 2. Comparing (7) with (8), there are 9 possible relations between $\left(p_{1 i}, p_{2 i}\right)$ and $\left(\left(2(B-K)+\left(\delta_{1}+\right.\right.\right.$ $\left.\left.\pi_{1 i}-\lambda\left(\delta_{2}+\pi_{2 i}\right)\right)\left(J_{12}+J_{2}\right)\right) / J-\pi_{1 i},\left(2(B-K)+\left(\lambda\left(\delta_{2}+\pi_{2 i}\right)-\right.\right.$ $\left.\left.\left.\delta_{1}-\pi_{1 i}\right)\left(J_{1}+J_{12}\right)\right) / \lambda J-\pi_{2 i}\right)$, which can be summarized in the following 7 different cases:
(I) If $p_{1 i} \geq\left(2(B-K)+\left(\delta_{1}+\pi_{1 i}-\lambda\left(\delta_{2}+\pi_{2 i}\right)\right)\left(J_{12}+J_{2}\right)\right) / J-\pi_{1 i}$ and $p_{2 i}>\left(2(B-K)+\left(\lambda\left(\delta_{2}+\pi_{2 i}\right)-\delta_{1}-\pi_{1 i}\right)\left(J_{1}+\right.\right.$ $\left.\left.J_{12}\right)\right) / \lambda J-\pi_{2 i}$, the investment of each enterprise in $\mathrm{R} \& \mathrm{D}$, equipment, and behavior is strictly larger than the optimal level. Therefore the total emission of enterprises will be strictly lower than the emission budget, $K$, and the total costs of enterprises will be strictly larger than that of the optimal level.

(II) If $p_{1 i} \leq\left(2(B-K)+\left(\delta_{1}+\pi_{1 i}-\lambda\left(\delta_{2}+\pi_{2 i}\right)\right)\left(J_{12}+J_{2}\right)\right) / J-\pi_{1 i}$ and $p_{2 i}<\left(2(B-K)+\left(\lambda\left(\delta_{2}+\pi_{2 i}\right)-\delta_{1}-\pi_{1 i}\right)\left(J_{1}+\right.\right.$ $\left.\left.J_{12}\right)\right) / \lambda J-\pi_{2 i}$, the result is contrary to that of $(\mathrm{I})$.

(III) If $p_{1 i}=\left(2(B-K)+\left(\delta_{1}+\pi_{1 i}-\lambda\left(\delta_{2}+\pi_{2 i}\right)\right)\left(J_{12}+\right.\right.$ $\left.\left.J_{2}\right)\right) / J-\pi_{1 i}$ and $p_{2 i}=\left(2(B-K)+\left(\lambda\left(\delta_{2}+\pi_{2 i}\right)-\delta_{1}-\right.\right.$ $\left.\left.\pi_{1 i}\right)\left(J_{1}+J_{12}\right)\right) / \lambda J-\pi_{2 i}$, the investment of individual enterprise is optimal; minimum cost is taken to meet the emission budget, $K$.

(IV) If $p_{1 i}>\left(2(B-K)+\left(\delta_{1}+\pi_{1 i}-\lambda\left(\delta_{2}+\pi_{2 i}\right)\right)\left(J_{12}+J_{2}\right)\right) / J-\pi_{1 i}$ and $p_{2 i}<\left(2(B-K)+\left(\lambda\left(\delta_{2}+\pi_{2 i}\right)-\delta_{1}-\pi_{1 i}\right)\left(J_{1}+\right.\right.$ $\left.\left.J_{12}\right)\right) / \lambda J-\pi_{2 i}$, the investment level in period 2 is lower than the optimal level.

(V) If $p_{1 i}>\left(2(B-K)+\left(\delta_{1}+\pi_{1 i}-\lambda\left(\delta_{2}+\pi_{2 i}\right)\right)\left(J_{12}+\right.\right.$ $\left.\left.J_{2}\right)\right) / J-\pi_{1 i}$ and $p_{2 i}=\left(2(B-K)+\left(\lambda\left(\delta_{2}+\pi_{2 i}\right)-\delta_{1}-\right.\right.$ $\left.\left.\pi_{1 i}\right)\left(J_{1}+J_{12}\right)\right) / \lambda J-\pi_{2 i}$, the investment in period 1 is strictly higher than the optimal level.

(VI) If $p_{1 i}<\left(2(B-K)+\left(\delta_{1}+\pi_{1 i}-\lambda\left(\delta_{2}+\pi_{2 i}\right)\right)\left(J_{12}+J_{2}\right)\right) / J-\pi_{1 i}$ and $p_{2 i}>\left(2(B-K)+\left(\lambda\left(\delta_{2}+\pi_{2 i}\right)-\delta_{1}-\pi_{1 i}\right)\left(J_{1}+\right.\right.$ $\left.\left.J_{12}\right)\right) / \lambda J-\pi_{2 i}$, the investment in period 2 is strictly higher than the optimal level.

(VII) If $p_{1 i}<\left(2(B-K)+\left(\delta_{1}+\pi_{1 i}-\lambda\left(\delta_{2}+\pi_{2 i}\right)\right)\left(J_{12}+J_{2}\right)\right) / J-\pi_{1 i}$ and $p_{2 i}=\left(2(B-K)+\left(\lambda\left(\delta_{2}+\pi_{2 i}\right)-\delta_{1}-\pi_{1 i}\right)\left(J_{1}+\right.\right.$ $\left.\left.J_{12}\right)\right) / \lambda J-\pi_{2 i}$, the investment in period 1 is strictly lower than the optimal level.

Proof of Property 3. If one enterprise gets its emission permits in period 1 through free of charge and in period 2 through auction, then the problem confronted by the enterprise is

$$
\begin{aligned}
\min _{x_{1 i}, x_{2 i}, y_{1 i}, y_{2 i}, e_{1 i}, e_{2 i}} & x_{1 i}+y_{1 i}+v_{i}\left(b_{1 i}-e_{1 i}-\alpha_{1 i} x_{1 i}^{1 / 2}-\beta_{1 i} y_{1 i}^{1 / 2}\right)^{2}-\pi_{1 i}\left(b_{1 i}-e_{1 i}\right) \\
& +\lambda\left[x_{2 i}+y_{2 i}+v_{i}\left(b_{2 i}-e_{2 i}-\alpha_{2 i} x_{1 i}^{1 / 2}-\theta_{2 i} x_{2 i}^{1 / 2}-\beta_{2 i} y_{1 i}^{1 / 2}-\phi_{2 i} y_{2 i}^{1 / 2}\right)^{2}+p_{2 i} e_{2 i}-\pi_{2 i}\left(b_{2 i}-e_{2 i}\right)\right] .
\end{aligned}
$$


As problem (A.6) is a special case of (P3) when $p_{1}=0$, then the solution to (P3) is also the solution to (A.6) with $p_{1}=0$; namely,

$$
\begin{aligned}
& \hat{x}_{1 i}=\left(\frac{\pi_{1 i}}{2} \alpha_{1 i}+\frac{\lambda\left(p_{2 i}+\pi_{2 i}\right)}{2} \alpha_{2 i}\right)^{2}, \\
& \hat{y}_{1 i}=\left(\frac{\pi_{1 i}}{2} \beta_{1 i}+\frac{\lambda\left(p_{2 i}+\pi_{2 i}\right)}{2} \beta_{2 i}\right)^{2}, \\
& \widehat{z}_{1 i}=\frac{1}{v_{i}}\left(\frac{\pi_{1 i}}{2}\right)^{2}, \\
& \widehat{x}_{2 i}=\left(\frac{p_{2 i}+\pi_{2 i}}{2} \theta_{2 i}\right)^{2}, \\
& \hat{y}_{2 i}=\left(\frac{p_{2 i}+\pi_{2 i}}{2} \phi_{2 i}\right)^{2}, \\
& \widehat{z}_{2 i}=\frac{1}{v_{i}}\left(\frac{p_{2 i}+\pi_{2 i}}{2}\right)^{2} .
\end{aligned}
$$

Similar to the proof of Property 2, Property 3 can be obtained by comparing (A.7) with (7).

Proof of Property 4. Similar to (7), the optimal solution to (P4) is

$$
\begin{aligned}
& \overline{\bar{x}}_{1 i}=\left(\frac{\pi_{1 i}+\lambda w}{2} \alpha_{1 i}+\frac{\lambda\left(w+\pi_{2 i}\right)}{2} \alpha_{2 i}\right)^{2}, \\
& \overline{\bar{y}}_{1 i}=\left(\frac{\pi_{1 i}+\lambda w}{2} \beta_{1 i}+\frac{\lambda\left(w+\pi_{2 i}\right)}{2} \beta_{2 i}\right)^{2}, \\
& \overline{\bar{z}}_{1 i}=\frac{1}{v_{i}}\left(\frac{\pi_{1 i}+\lambda w}{2}\right)^{2}, \\
& \overline{\bar{x}}_{2 i}=\left(\frac{w+\pi_{2 i}}{2} \theta_{2 i}\right)^{2} \\
& \overline{\bar{y}}_{2 i}=\left(\frac{w+\pi_{2 i}}{2} \phi_{2 i}\right)^{2}, \\
& \overline{\bar{z}}_{2 i}=\frac{1}{v_{i}}\left(\frac{w+\pi_{2 i}}{2}\right)^{2} .
\end{aligned}
$$

In unilateral trading, the investment of individual enterprise is optimal only when the investment in each pathway is the same. In other words, (A.8) must be the same as (7); namely,

$$
\begin{aligned}
\pi_{1 i}+\lambda w \\
=\frac{2(B-K)+\left(\delta_{1}+\pi_{1 i}-\lambda\left(\delta_{2}+\pi_{2 i}\right)\right)\left(J_{12}+J_{2}\right)}{J}, \\
\lambda\left(\pi_{2 i}+w\right) \\
=\frac{2(B-K)+\left(\lambda\left(\delta_{2}+\pi_{2 i}\right)-\delta_{1}-\pi_{1 i}\right)\left(J_{1}+J_{12}\right)}{J} .
\end{aligned}
$$

(A.9) implies

$$
\begin{aligned}
& \frac{\left(\delta_{1}+\pi_{1 i}-\lambda\left(\delta_{2}+\pi_{2 i}\right)\right)\left(J_{12}+J_{2}\right)}{J}-\pi_{1 i} \\
& =\frac{\left(\lambda\left(\delta_{2}+\pi_{2 i}\right)-\delta_{1}-\pi_{1 i}\right)\left(J_{1}+J_{12}\right)}{J}-\lambda \pi_{2 i} .
\end{aligned}
$$

Notice $J=J_{1}+2 J_{12}+J_{2}$; we can obtain the following equality from (A.10):

$$
\delta_{1}=\lambda \delta_{2} .
$$

By (A.9) and (A.11), we can judge that investment in (A.8) can never be equal to that in (7) if $\delta_{1} \neq \lambda \delta_{2}$. If $\delta_{1}=\lambda \delta_{2}$, we can get from (A.9) that $w=\left(2(B-K)-\pi_{1 i}\left(J_{1}+J_{12}\right)-\lambda \pi_{2 i}\left(J_{12}+J_{2}\right)\right) / \lambda J$, in which case (A.8) is equal to (7).

Proof of Property 5. Similar to (7), the optimal solution to (P5) in bilateral trading is

$$
\begin{aligned}
& \tilde{\tilde{x}}_{1 i}=\frac{1}{4}\left(\left(w_{1}+\pi_{1 i}\right) \alpha_{1 i}+\lambda\left(w_{2}+\pi_{2 i}\right) \alpha_{2 i}\right)^{2}, \\
& \tilde{\tilde{y}}_{1 i}=\frac{1}{4}\left(\left(w_{1}+\pi_{1 i}\right) \beta_{1 i}+\lambda\left(w_{2}+\pi_{2 i}\right) \beta_{2 i}\right)^{2}, \\
& \tilde{\widetilde{z}}_{1 i}=\frac{1}{4 \nu_{i}}\left(w_{1}+\pi_{1 i}\right)^{2}, \\
& \tilde{\widetilde{x}}_{2 i}=\frac{1}{4} \theta_{2 i}^{2}\left(w_{2}+\pi_{2 i}\right)^{2}, \\
& \tilde{\tilde{y}}_{2 i}=\frac{1}{4} \phi_{2 i}^{2}\left(w_{2}+\pi_{2 i}\right)^{2}, \\
& \tilde{\widetilde{z}}_{2 i}=\frac{1}{4 v_{i}}\left(w_{2}+\pi_{2 i}\right)^{2} .
\end{aligned}
$$

Comparing (A.12) with (7), we get that the best investment of enterprise $i$ in bilateral mode is

$$
\begin{aligned}
& \pi_{1 i}+w_{1} \\
& =\frac{2(B-K)+\left(\delta_{1}+\pi_{1 i}-\lambda\left(\delta_{2}+\pi_{2 i}\right)\right)\left(J_{12}+J_{2}\right)}{J}, \\
& \lambda\left(\pi_{2 i}+w_{2}\right) \\
& =\frac{2(B-K)+\left(\lambda\left(\delta_{2}+\pi_{2 i}\right)-\delta_{1}-\pi_{1 i}\right)\left(J_{1}+J_{12}\right)}{J} .
\end{aligned}
$$

From (A.13), we get that if $\delta_{1}=\lambda \delta_{2}$, then

$$
\begin{aligned}
w_{1} & =\lambda w_{2} \\
& =\frac{2(B-K)-\pi_{1 i}\left(J_{1}+J_{12}\right)-\lambda \pi_{2 i}\left(J_{12}+J_{2}\right)}{J} .
\end{aligned}
$$

In such case, (A.12) is equivalent to (7). If $\delta_{1} \neq \lambda \delta_{2}$, the proof of Property 5 is similar to Property 2.

\section{Conflict of Interests}

The authors declare that there is no conflict of interests regarding the publication of this paper. 


\section{Acknowledgments}

This work was supported partly by the National Natural Science Foundation of China (no. 71471039), National Social Science Foundation of China (no. 12CJY078), and Program for Academic Innovative Research Team in Beijing (no. IDHT20130522).

\section{References}

[1] F. Jotzo and J. C. V. Pezzey, "Optimal intensity targets for greenhouse gas emissions trading under uncertainty," Environmental and Resource Economics, vol. 38, no. 2, pp. 259-284, 2007.

[2] L. Lan, "China to create national carbon-trading market," China Daily, 2015.

[3] D. Zhang, V. J. Karplus, C. Cassisa, and X. Zhang, "Emissions trading in China: progress and prospects," Energy Policy, vol. 75, pp. 9-16, 2014.

[4] G. Klepper and S. Peterson, "The EU emissions trading scheme allowance prices, trade flows and competitiveness effects," European Environment, vol. 14, no. 4, pp. 201-218, 2004.

[5] K. Neuhoff, K. K. Martinez, and M. Sato, "Allocation, incentives and distortions: the impact of EU ETS emissions allowance allocations to the electricity sector," Climate Policy, vol. 6, no. 1, pp. 1-32, 2006.

[6] D. Demailly and P. Quirion, "European Emission Trading Scheme and competitiveness: a case study on the iron and steel industry," Energy Economics, vol. 30, no. 4, pp. 2009-2027, 2008.

[7] M. Wang, M. Wang, and S. Y. Wang, "Optimal investment and uncertainty on China's carbon emission abatement," Energy Policy, vol. 41, no. 2, pp. 871-877, 2012.

[8] E. Massetti and M. Tavoni, "A developing Asia emission trading scheme (Asia ETS)," Energy Economics, vol. 34, no. 3, pp. S436S443, 2012.

[9] M. Wang, M. Wang, C. Dang, and S. Wang, "A pareto optimal auction mechanism for carbon emission rights," Mathematical Problems in Engineering, vol. 2014, Article ID 438104, 7 pages, 2014.

[10] M. Wang, M. Wang, Y. Hu, and C. Dang, "Efficient auction mechanisms for carbon emission trading scheme," International Journal of Global Energy Issues, vol. 39, no. 1-2, pp. 108-127, 2016.

[11] Q. Wu, "Policy and politics of a carbon market in China," in Greenhouse Gas Market Report 2011: Asia and Beyond: the Roadmap to Global Carbon \& Energy Markets, J. Peetermans, Ed., pp. 22-25, International Emissions Trading Association, Geneva, Switzerland, 2011.

[12] J. M. Poterba, "Tax policy toward global warming: on designing a carbon tax," in Economic Policy Responses to Global Warming, R. Dornbusch and J. Poterba, Eds., pp. 71-97, MIT Press, Cambridge, UK, 1991.

[13] M. Hoel, "Should a carbon tax be differentiated across sectors?" Journal of Public Economics, vol. 59, no. 1, pp. 17-32, 1996.

[14] E. Worrell, L. Price, and N. Martin, "Energy efficiency and carbon dioxide emissions reduction opportunities in the US iron and steel sector," Energy, vol. 26, no. 5, pp. 513-536, 2001.

[15] M. A. Brown, "Market failures and barriers as a basis for clean energy policies," Energy Policy, vol. 29, no. 14, pp. 1197-1207, 2001.

[16] H. J. Herzog, "Peer reviewed: what future for carbon capture and sequestration?" Environmental Science \& Technology, vol. 35, no. 7, pp. 148-153, 2001.
[17] M. A. Kromer, A. Bandivadekar, and C. Evans, "Long-term greenhouse gas emission and petroleum reduction goals: evolutionary pathways for the light-duty vehicle sector," Energy, vol. 35, no. 1, pp. 387-397, 2010.

[18] J. Jönsson and J. Algehed, "Pathways to a sustainable European kraft pulp industry: trade-offs between economy and $\mathrm{CO}_{2}$ emissions for different technologies and system solutions," Applied Thermal Engineering, vol. 30, no. 16, pp. 2315-2325, 2010.

[19] A. S. Dagoumas and T. S. Barker, "Pathways to a low-carbon economy for the UK with the macro-econometric E3MG model," Energy Policy, vol. 38, no. 6, pp. 3067-3077, 2010.

[20] Y. Lu, A. Stegman, and Y. Cai, "Emissions intensity targeting: from China's 12th Five Year Plan to its Copenhagen commitment," Energy Policy, vol. 61, pp. 1164-1177, 2013.

[21] W. Chen, "Five-year plan outline 'promising,' China Daily, December 2015, http://www.chinadaily.com.cn/kindle/2015-12/ 10/content_22680660.htm.

[22] P. W. Kennedy, "Optimal early action on greenhouse gas emissions," Canadian Journal of Economics, vol. 35, no. 1, pp. $16-$ 35, 2002.

[23] I. W. H. Parry and M. Toman, "Early emissions reduction programs: an application to $\mathrm{CO}_{2}$ policy," Discussion Paper 0026, Resources for the Future, 2000.

[24] R. B. Zhang, "Ministry of Industry and Information Technology: 'twelfth-five' energy saving and emission reduction measures," in Proceedings of the Creation Conference on Science and Technology of China International Industrial Energy Saving \& Pollution Reduction, Beijing, China, May 2010.

[25] Z. Dai and F. Wen, "Robust CVaR-based portfolio optimization under a genal affine data perturbation uncertainty set," Journal of Computational Analysis \& Applications, vol. 16, no. 1, pp. 93103, 2014

[26] F. Wen, Z. He, X. Gong, and A. Liu, "Investors' risk preference characteristics based on different reference point," Discrete Dynamics in Nature and Society, vol. 2014, Article ID 158386, 9 pages, 2014.

[27] F. Wen, Z. He, Z. Dai, and X. Yang, "Characteristics of investors' risk preference for stock markets," Economic Computation and Economic Cybernetics Studies and Research, vol. 3, no. 48, pp. 235-254, 2014 


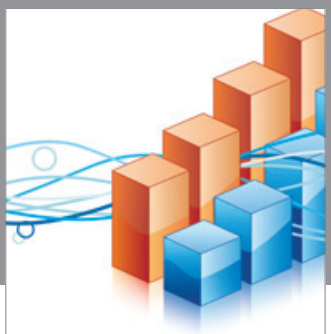

Advances in

Operations Research

vatem alat4

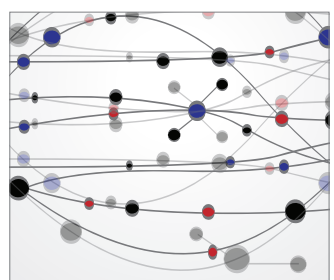

\section{The Scientific} World Journal
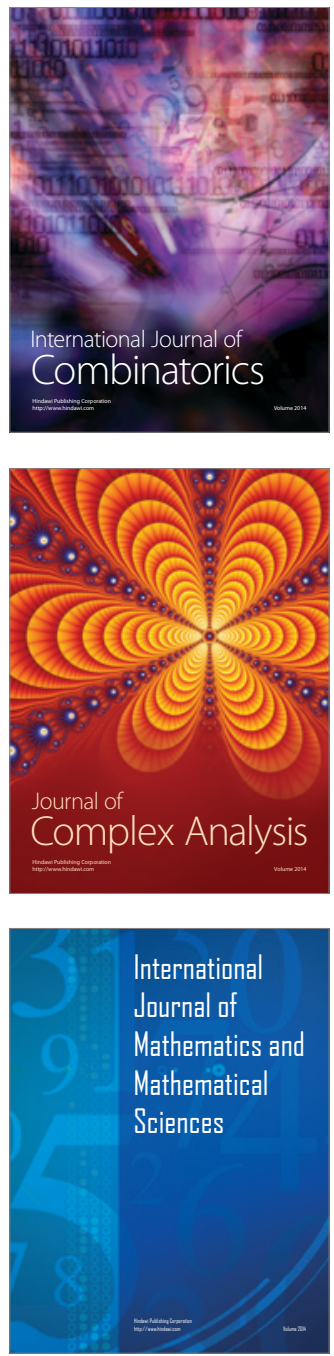
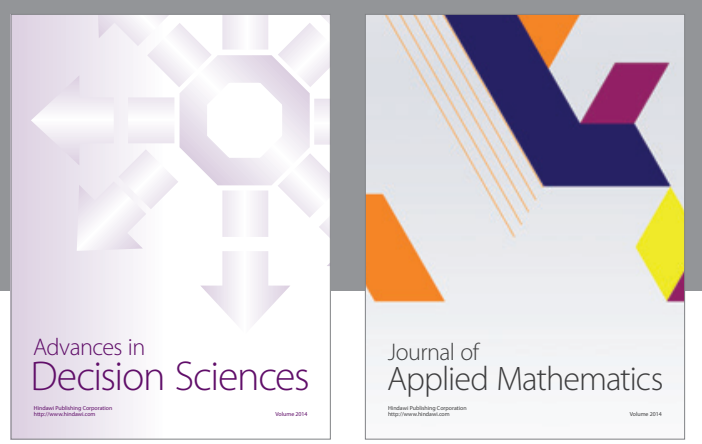

Algebra

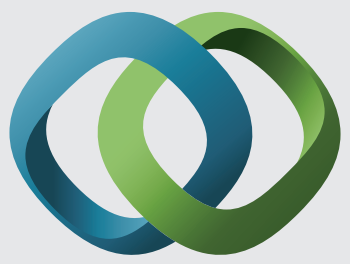

\section{Hindawi}

Submit your manuscripts at

http://www.hindawi.com
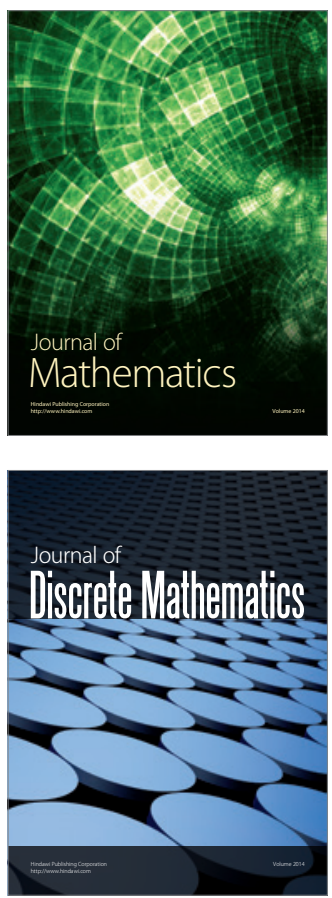

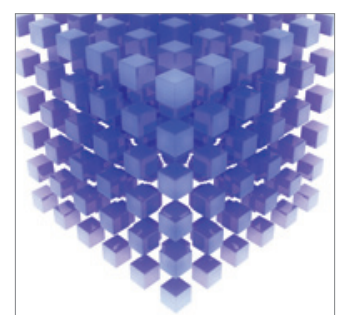

Mathematical Problems in Engineering
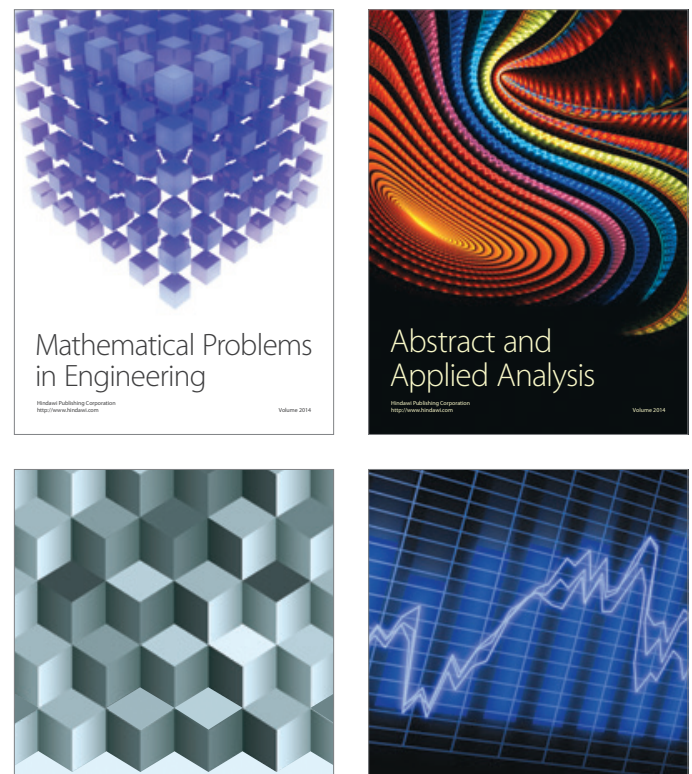

Journal of

Function Spaces

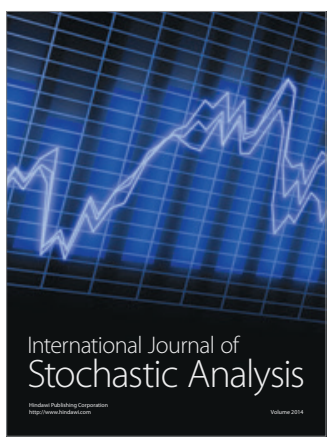

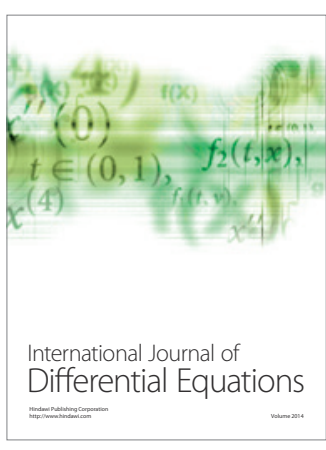
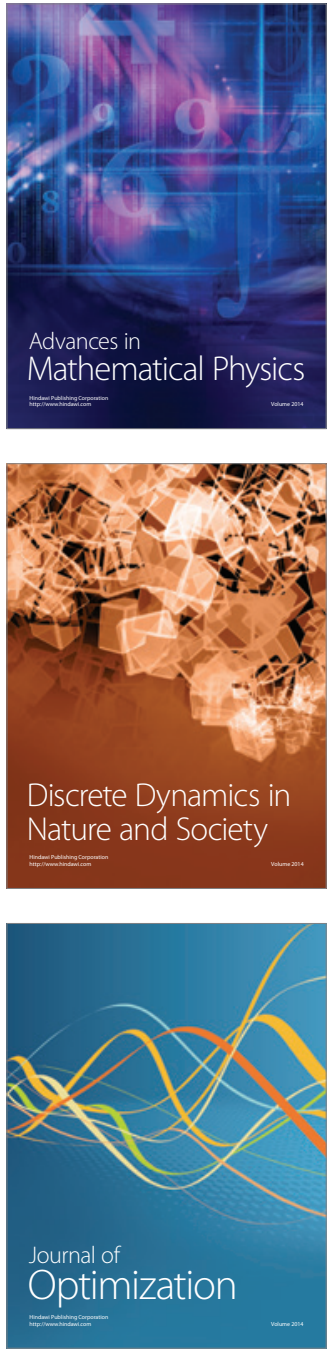